\title{
O USO DE TECNOLOGIAS DA INFORMAÇÃO NA GESTÃO DA SEGURANÇA URBANA: OLHARES SOBRE O SISTEMA DE MONITORAMENTO POR IMAGENS DO MUNICÍPIO DE CAPÃO DA CANOA - RS
}

\section{THE USE OF INFORMATION TECHNOLOGIES IN URBAN SECURITY MANAGEMENT: LOOKS ON THE IMAGE MONITORING SYSTEM OF CAPÃO DA CANOA CITY}

\author{
Juarez Camargo Borges \\ Desenvolvimento Regional. \\ E-mail: \\ juarezcamargoborges@gmail.com \\ Josi Rosa de Oliveira \\ Educação. \\ E-mail: josi.montanet@gmail.com
}

\section{RESUMO}

Este estudo de natureza qualitativa e bibliográfica, objetivou investigar como a tecnologia da informação pode contribuir para a gestão da segurança urbana, identificando a eficiência do seu uso e apresentando algumas de suas contribuições. Para tanto, utilizou-se como objeto de estudo o Gabinete de Gestão Integrada do Município de Capão da Canoa/RS. Os resultados apontaram benefícios à gestão municipal em termos de segurança pública, mas que precisam avançar em outros aspectos relacionados não somente ao controle da violência. Sugere-se a criação de indicadores mais abrangentes para avaliar a eficiência e a ampliação do projeto.

Palavras-Chave: Segurança Urbana, Tecnologia da Informação, Indicadores de Controle.

\begin{abstract}
This qualitative and bibliographic study had objective to investigate how information technology can contribute to the management of the urban security, identifying the efficiency in his use and presenting some of contributions. To this end, we used as object of study the Integrated Management Office of Capão da Canoa city. The results pointed to benefits to city management in terms of public safety, but that need to advance in other aspects related not only to the control of violence. It's suggested a more comprehensive indicators creation to assess the project efficiency and scale.
\end{abstract}

Keywords: Urban Security, Information Technologies, Control Indicators. 


\section{INTRODUÇÃO}

Hoje em dia, quando fala-se em gestão das cidades, gestores públicos e estudiosos concordam que não é tarefa fácil por conta da burocracia do sistema, pelos recursos necessários e pela má gestão destes recursos por alguns gestores.

Outro fator importante é o crescimento das cidades que nem sempre ocorre ordenadamente, com planejamento e pensando no futuro, ou seja, um crescimento com desenvolvimento e sustentabilidade.

Espera-se da gestão das cidades que aconteçam com qualidade, que os espaços sejam destinados às pessoas e suas culturas, que haja ordenamento e que empresas e cidadãos tenham plena participação nas decisões que os afetem. Por tudo isso e pelo conflito de interesses que se percebe na vivência urbana, gestores públicos precisam pensar em um modelo de gestão que possibilite a participação da comunidade civil, das empresas privadas e que isso viabilize uma cidade cuja arquitetura caminhe para o conceito de "cidade inteligente".

Trataremos em capítulo posterior os pressupostos teóricos sobre as cidades inteligentes, mas pode-se dizer que se trata de um modelo de gestão pública que se apropria da tecnologia para buscar soluções para as cidades, tornando-as sustentáveis e ágeis em seus processos, otimizando os diferentes recursos. Desta forma, a gestão da cidade deve levar em consideração também as influências do mercado, o planejamento deve estar fundamentado nos princípios da igualdade e equidade, entendendo que a cidade é para todos. (BARROSO, 2012) O conceito de cidade inteligente e a maneira como pode ser implementado na gestão das cidades, pode ser visto em todo o mundo.

$\mathrm{Na}$ tentativa de encontrar soluções inovadoras, o Governo de inúmeras cidades buscou, por meio de investimentos em tecnologias da informação e comunicação, transformar o espaço urbano proporcionando melhor qualidade de vida aos moradores e melhorando a funcionalidade da estrutura da cidade em relação a mobilidade urbana, proteção e conservação do patrimônio público, meio ambiente e patrulhamento por mais segurança dentro da cidade.

Diante da capacidade de inovação no planejamento e gestão do território urbano e utilizando o conceito de cidade inteligente, é importante desenvolver estudos que busquem identificar os modelos já existentes e os principais benefícios alcançados com a implementação da tecnologia na gestão das cidades. 
Neste sentido, este estudo procurou investigar como a tecnologia da informação pode contribuir para a gestão da segurança urbana, identificando a eficiência do seu uso, e apresentando algumas contribuições. A pesquisa teve como objeto de análise, o sistema de monitoramento por imagens do município de Capão da Canoa/RS.

Procurou-se, por meio bibliográfico e análise de um sistema de monitoramento por câmeras, observar a estrutura, contingente necessário ao seu funcionamento e a forma de realização do processo, controle e avaliação de resultados.

O texto apresenta uma breve revisão sobre a gestão do espaço urbano, modelo de segurança pública com uso de tecnologias e sistema de monitoramento por câmeras. Buscou-se compreender o conceito de cidade inteligente, ou a transformação da cidade em "cidade digital". E por fim, os autores apresentam uma análise das contribuições do sistema utilizado em Capão da Canoa apontando a necessidade de implementação de indicadores de controle de resultados.

\section{GESTÃO DO ESPAÇO URBANO}

A Constituição Federal de 1988 em seu artigo 182, regulamentada pelo Estatuto das Cidades, prevê que os municípios se responsabilizem pelo planejamento e execução de políticas públicas de gestão urbana. “Art. 182 - A política de desenvolvimento urbano, executada pelo poder público municipal, conforme diretrizes gerais fixadas em lei, tem por objetivo ordenar o pleno desenvolvimento das funções sociais da cidade e garantir o bem-estar de seus habitantes. (BRASIL, 1988). Neste aspecto, pode-se dizer que os espaços públicos se traduzem em função do gerenciamento direto dos municípios.

Por espaço público pode-se entender, inicialmente, que é o "lugar, praça, rua, shopping, praia, qualquer tipo de espaço, onde não haja obstáculos à possibilidade de acesso e participação de qualquer tipo de pessoa". (GOMES, 2010, p. 162). E é neste espaço que se encontram muitas diferenças e afinidades, diferentes expectativas e interesses da vida social urbana. Espaço público também "é um lugar de conflitos, de problematização da vida social”. (GOMES, 2010, p. 164).

Nery (2019, p.01) aponta que "a sociedade é produzida por mudanças sociais, convergentes em certos aspectos e divergentes em outros", o que reflete em novas formas de organização e gestão do espaço urbano. E neste cenário a gestão pública tem talvez 
seu maior desafio em estabelecer códigos de conduta para que seja exercida a cidadania dos usuários do espaço urbano.

Sobre a cidadania, Gomes esclarece que:

\begin{abstract}
A cidadania é um pacto social estabelecido simultaneamente como uma relação de pertencimento a um grupo e a um território. Este pacto associativo é formal e pretende assegurar os direitos e deveres de cada indivíduo. (GOMES, 2010, p. 173)
\end{abstract}

Neste sentido podemos entender que o uso de monitoramento na gestão do patrimônio público pode vir a sinalizar os problemas dos espaços públicos com práticas contrárias ao exercício da cidadania. Como exemplo, cita-se as depredações do patrimônio e o descarte de lixo em locais incorretos.

\title{
2.1 A TECNOLOGIAEA GESTÃO DO ESPAÇO URBANO
}

O avanço tecnológico pode ser percebido pelo aumento do nível de interação humana com a tecnologia e os impactos positivos no cotidiano das pessoas. "As tecnologias de informação e comunicação - TICs - oferecem maneiras eficientes de processar e trocar informações com diversos objetivos". (BARBOSA; SILVA, 2010, p. 02). É possível perceber um aumento acelerado do uso das tecnologias de informação nas mais diversas áreas, como é o caso da comunicação em grandes distâncias geográficas, permitindo, no campo da política, uma maior interação com eleitores através dos web sites dos partidos políticos. Neste sentido o avanço tecnológico tem permitido que "muitas relações do Estado com a população sejam mediadas pelas TICs, o que tem sido chamado de governo eletrônico". (BARBOSA; SILVA, 2010, p. 04).

\footnotetext{
Algumas prefeituras fazem uso de sistemas de informação geográficas na gestão de seus municípios, como o uso de imagens de satélites para verificar construções irregulares, para analisar o fluxo de veículos e reestruturar o tráfego nas vias. (BARBOSA; SILVA, 2010, p. 04).
}

De acordo com o tema central deste estudo é importante compreender como o avanço tecnológico impacta positivamente na gestão do espaço urbano com a possibilidade de monitoramento do espaço urbano e transmissão de imagens em tempo real fortalecendo as ações de segurança pública dentro do recorte territorial deste estudo.

\subsubsection{Segurança pública e os meios tecnológicos na gestão das cidades}


Algumas estratégias de gestão precisam ser adotadas para gestão das cidades. "A cidade necessita de uma organização mínima que cumpra certas exigências para a vida em comum: trabalho, serviços de saúde, ensino, cultura e segurança”. (GONÇALVES, 2016, p. 07).

A segurança pública pode ser entendida como meio pelo qual impõe proteção à vida e aos direitos e liberdades fundamentais de cada indivíduo, efetivando, estabelecendo, um convívio pacífico e harmonioso em sociedade. Consequentemente, a segurança pública é um direito fundamental que assegura o gozo de inúmeros outros direitos previstos no ordenamento jurídico. (RODRIGUES APUD MINUSCOLI; ALMEIDA, 2016).

"No Brasil, a responsabilidade pela segurança pública na cidade é estadual, e operacionalizada pelas secretarias de segurança pública e pela atuação das polícias civil e militar. (CUNHA et al, 2016, P. 81)". A Constituição Federal de 1988 em seu artigo 144 normatizou a segurança pública, e de acordo com o texto constitucional temos:

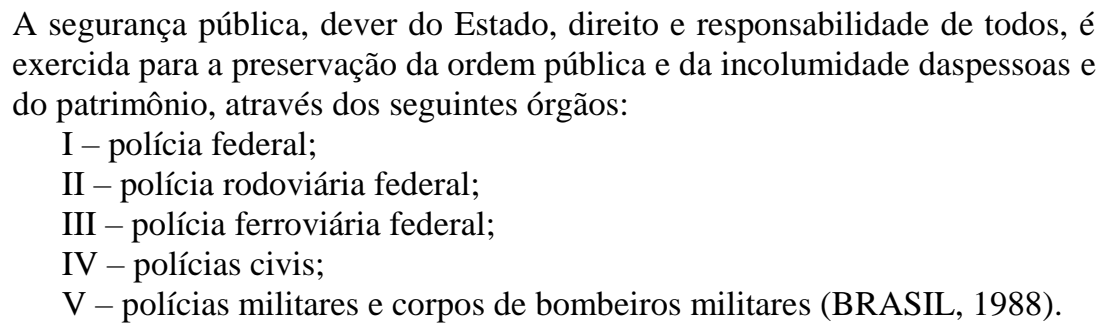

O texto destaca uma autonomia para os estados em conduzir a políticade segurança. A prevenção à violência e à ordem pública se tornaram atribuições das instituições policiais, todavia, percebe-se que estes órgãos não estão conseguindo dar conta das demandas que se apresentam, especialmente na esfera municipal, onde a vida dos cidadãos acontece. A lei diz também ser a segurança pública um direito, mas também responsabilidade de todos. Pode-se com isso supor que os municípios precisam se apropriar de ferramentas que auxiliem na gestão da segurançada cidade e por consequência uma melhor qualidade de vida para o munícipe.

Para os cidadãos brasileiros, o aspecto segurança urbana ocupa primeiro lugar em relação aos demais âmbitos quanto à sua importância. Quando indagados sobre quais ações de melhoria recomendaria para fazer das cidades espaços mais seguros, as seis evocações destacadas foram: eficácia policial, vigilância, mais segurança, endurecer a legislação, conscientizar o cidadão e melhorar a iluminação pública. (CUNHA et al, 2016, p. 65). 
O município que pretende transformar-se em espaço de harmonia para seus cidadãos, onde todos possam conviver respeitando os direitos individuais, deve oferecer e garantir a segurança pública, abrangente a todas as pessoas, protegendo-as.

Na gestão das cidades uma das principais contribuições na tecnologia foi "trazer para dentro das cidades conceitos e práticas anteriormente existentes apenas no mercado corporativo onde a população representava a figura do cliente, e a cidade a figura do prestador de serviço". (JORDÃO, 2016, p. 39). Assim a tecnologia é implementada na gestão do espaço urbano para trazer qualidade aos serviços prestados, com ferramentas tecnológicas dinamizando o processo de gestão do território urbano com mais eficiência.

A segurança urbana se tornou uma problemática na gestão da cidade e cada região apresenta sua particularidade. Diante disso destaca-se que "novas tecnologias digitais contribuem com a criação de ambientes urbanos mais protegidos, na tentativa de tornálos mais seguros aos cidadãos" (CUNHA et al, 2016, p. 81).

A interconectividade dentro do município e a troca de experiências entre as cidades é uma alternativa para melhorar a eficiência e a qualidade de vida. A autora apresenta como exemplo o ocorre na cidade do Rio de Janeiro. É um exemplo de projeto bem-sucedido nesse sentido. "A interconectividade entre polícia civil, bombeiros, engenharia de tráfico, ambulância e prefeitura, através do monitoramento online (através de centenas de sensores espalhados em pontos estratégicos da cidade) garantem fluidez e ação rápida no trânsito da cidade”. (JORDÃO, 2016, p. 56).

De acordo com o Gaúcha ZH/RS de junho de 2018, tendo como fonte a Secretaria de Segurança Pública (SSP), um em cada quatro municípios do Estado do Rio grande do Sul (RS), conta com monitoramento por câmeras para o combate à criminalidade, em pleno funcionamento, totalizando 113 municípios. (GAÚCHA/RS, 2018). Todavia, muitos outros municípios estão em fase de projeto e implantação.

Dos municípios do RS, cita-se como exemplo a cidade de Canoas que, sendo a quarta maior cidade do Estado, desde dezembro de 2015, possui um centro integrado de comando e controle que, em parceria com oficiais da reserva da Brigada Militar, acompanham as imagens transmitidas pelas mais de 200 câmeras de vigilância instaladas em diferentes bairros do município. O OSPC -Observatório de Segurança Pública de Canoas, de acordo com as informações disponíveis na página oficial da prefeitura, foi instituído pela Lei Municipal $\mathrm{N}^{\circ} 5386 / 2009$, mas iniciou suas atividades em 2010. O 
OSPC foi formado por sociólogos e geógrafos com um perfil aplicado à prática e às ferramentas de inteligência (como os softwares de análises estatísticas e de georreferenciamento, além das inovadoras técnicas de pesquisa). Pode-se dizer que se constitui num centro de pesquisa social aplicada à segurança pública. Iniciou suas atividades com recursos do Programa Nacional de Segurança Pública (PRONASCI), da Secretaria Nacional de Segurança Pública do Ministério da Justiça, e da Prefeitura Municipal de Canoas, e transformado em política pública através da Lei Municipal $\mathrm{n}^{\circ}$ 5386. Hoje, financiado pela Prefeitura, qualifica e aperfeiçoa as atividades realizadas pelo Gabinete de Gestão Integrada Municipal (GGI-M), sendo atualmente executado pela Fundação LaSalle. (CANOAS, 2019)

O observatório é uma ferramenta que possibilita indicadores criminais monitorados, tais como: Mortes Violentas, Violência contra a Mulher, Furto e Roubo de Veículos e ainda de violência escolar, permitindo realizar diagnósticos e ações pontuais preventivas em conjunto com outras secretarias do município. O município de Canoas conta ainda com instituições estaduais que são fonte de informações para os indicadores, como a Polícia Civil, a Polícia Militar e a Secretaria de Segurança Pública do Estado, bem como órgãos da administração pública municipal, como a Secretaria de Educação, de Saúde, de Desenvolvimento Social, o Centro de Referência para Mulheres, o Instituto Canoas XXI, entre outros. (CANOAS, 2019)

No litoral norte do Rio Grande do Sul um dos aspectos com bastante fragilidade é a segurança pública, porque a falta desta e os altos índices de criminalidade estão sempre no centro dos debates da gestão pública. "A taxa de roubos e furtos é a soma dos dados de roubos de carro e furtos de carro para cada mil habitantes da localidade". (COREDE, 2017, p.51) Com base no ano de 2014, observou-se nas taxas de roubos e furtos, que o Rio Grande do Sul teve uma taxa geral de 23,5enquanto o litoral ficou com 34,3 bem superior ao índice do Estado no período analisado.

O estudo também aponta algumas ameaças ao desenvolvimento da região, como os impactos do turismo ao meio ambiente e a baixa temporada que impacta na economia dos municípios. No aspecto social, o baixo efetivo policial, os altos índices de drogadição e a permanência de famílias oriundas de outras cidades no período de baixa temporada provocam grandes desafios à gestão pública municipal quanto à segurança e à saúde pública. 
O grande mérito desses estudos foi justamente ter demonstrado as relações entre o desenvolvimento econômico-social e o movimento do crime, destacando a tendência de alguns delitos serem maiores naqueles locais em que se observa maior precariedade da infraestrutura urbana, caracterizada por pior oferta de postos de trabalho, serviços de lazer e cultura. Além disso, também evidenciaram a possível influência da crise econômica no ingresso de novos indivíduos em grupos delinquentes. (NERY, 2019, P. 01).

É importante destacar que entre o rural e o urbano, os municípios litorâneos são, na sua maioria, urbanos e, como tal, apresentam características negativas e positivas que são próprias dos municípios urbanos. Como fatores positivos pode-se citar o acesso facilitado à educação, saúde e serviços públicos. Já como aspectos negativos, aponta-se os problemas ligados às mazelas sociais como drogas, pobreza, roubos, furtos, falta de habitação e poluição. Esses aspectos prejudicam um planejamento urbano territorial eficiente e eficaz. (COREDE, 2010).

Destaca-se no intraurbano os aspectos demográficos, econômicos e sociais que estão relacionadas com as condições de vida específica de cada grupo social, em cada local. Conforme Nery $(2019$, p.01) “considerar as distinções do espaço urbano constituise uma das estratégias fundamentais para o entendimento dos aspectos sociais na urbe, de sua variabilidade e variação ao longo do tempo". Neste sentido é importante conhecer as características do lugar para então desenvolver ações que promovam a segurança urbana e a qualidade de vida.

\subsection{CIDADES INTELIGENTES}

A terminologia de cidade inteligente começou a ser utilizada a partir dos anos 2000, tratando principalmente da eficiência da gestão e dos serviços públicos nas cidades. Dentro deste conceito destaca-se o entendimento da cidade como um organismo vivo que apresenta a interconexão entre a estrutura física, os habitantes e o meio econômico. Neste contexto a tecnologia passa a assumir papel importante, com grandes potencialidades e oportunidades para administração e gestão das cidades nas áreas da saúde, educação, segurança, transporte e demais serviços públicos. (JORDÃO, 2016).

Dassen destaca a definição de uma cidade inteligente, de acordo com a classificação do relatório da União Europeia (UE) é: "uma cidade inteligente é uma cidade que procura resolver as questões públicas mediante soluções que utilizam TIC, com base 
em parcerias de múltiplas partes interessadas baseadas no município”. (DASSEN, 2014, P.140).

Ressalta-se que "o termo Smart City vai muito mais além que a disponibilização de pontos de Wi-Fi grátis em determinados ambientes públicos, como praças e prédios do governo". (TELIUM, 2018, p. 01). O conceito de cidade inteligente busca repensar a cidade de forma integrada e, por meio da tecnologia, encontrar soluções para problemas como: desperdício de recursos, tempo e dinheiro público. "Cidades inteligentes são locais aonde se promove uma integração do desenvolvimento entre diferentes aspectos da vida urbana, sejam eles físicos ou virtuais”. (JORDÃO, 2016, p. 39). Para isto é preciso uma integração entre os moradores e os equipamentos da cidade de forma simples, rápida e segura.

O uso e aplicação desse conceito é possível através da Internet das Coisas (IoT), o uso de dispositivos inteligentes e conectados à internet, possibilita, não apenas uma comunicação direta entre os equipamentos, mas também entre os operadores. Neste sentido a IoT tem um papel fundamental para as SmartCities. Contudo, ainda existe um grande desafio a ser enfrentado que é a qualidade da conectividade que nem sempre se apresenta eficiente em todo o território. (TELIUM, 2018).

\footnotetext{
O principal objetivo da implantação de uma cidade inteligente é otimizar a capacidade de gestão geral sobre todos os aspectos do espaço público. Também melhorar significativamente a qualidade de vida dos que nela habitam com o auxílio das novas tecnologias, sobretudo internet das coisas. (TELIUM, 2018, p. 01).
}

No Brasil a implementação de TIC no contexto das cidades se deu a partir marco regulatório o decreto 7.715/2010, através do programa nacional de banda larga, cujo objetivo inicial foi o de promover o desenvolvimento econômico e social e a inclusão digital; gerar emprego e renda e a competitividade tecnológica do país. E na sequência em 2011 o governo federal reconheceu a necessidade de maiores investimentos em TIC para, de fato, promover a inclusão digital, desafio ainda a ser superado.

O tema cidade inteligente só foi abordado em 2016 com o decreto 8.776/2016 prevendo a universalização da internet no país e desta forma tratou-se questões de integração de iniciativas já existentes nos municípios, modernização da administração pública, difusão dos conhecimentos e serviços tecnológicos. (JORDÃO, 2016). 
Revista Tecnologia e Ambiente, v. 27, 2021, Criciúma, Santa Catarina/SC - ISSN Eletrônico

2358-9426 e ISSN Impresso 1413-8131

do Brasil.

A seguir o quadro 1 apresenta algumas ações implementadas por capitais e cidades

Quadro 1: Cidades inteligentes no Brasil

\begin{tabular}{|l|l|}
\hline CIDADE & AÇÕES \\
\hline Rio de Janeiro & Centro de operações com foco em segurança pública e gestão de tráfego. \\
\hline Curitiba & Solução M2M (Machine to Machine) no transporte público. \\
\hline São José dos Campos & Câmeras instaladas com monitoramento 24 horas por dia, 7 dias da semana. \\
\hline Águas de São Pedro & $\begin{array}{l}\text { Estacionamento inteligente. } \\
\text { Serviços públicos pela internet (acompanhamento do desempenho na escola e } \\
\text { marcar consultas). } \\
\text { Fibra óptica. }\end{array}$ \\
\hline São Paulo & Diversidade em mobilidade urbana. \\
\hline Santos & $\begin{array}{l}\text { Semáforos em tempo real em 49 cruzamentos da cidade. } \\
\text { Projetos voltados para a mobilidade e inovação do município. }\end{array}$ \\
\hline Belo Horizonte & $\begin{array}{l}\text { Serviços informativos ao cidadão. } \\
\text { Eficiência energética } \\
\text { Qualidade de vida. } \\
\text { Projetos em sustentabilidade. }\end{array}$ \\
\hline
\end{tabular}

Fonte: Adaptado de Jordão (2016, p. 60).

Alguns indicadores globais permitem medir o nível da cidade inteligente, Jordão

(2016, p. 61) apresenta onze destes indicadores e como podem ser vistos no Brasil cada

um deles.

Quadro 2: Avaliação do conceito cidades inteligentes no Brasil

\begin{tabular}{|l|l|}
\hline INDICADORES & AVALIAÇÃO NO BRASIL \\
\hline $\begin{array}{l}\text { Infraestrutura em } \\
\text { Telecomunicações }\end{array}$ & $\begin{array}{l}\text { Através do programa cidade digital apenas 71 municípios brasileiros foram } \\
\text { atendidos, existe a necessidade de expandir para muitos outros municípios. }\end{array}$ \\
\hline $\begin{array}{l}\text { Serviços voltados para melhorar } \\
\text { a qualidade de vida do cidadão }\end{array}$ & $\begin{array}{l}\text { Exemplo bem sucedido do cartão cidadão na cidade de Barueri, entretanto, existe } \\
\text { a necessidade de expandir para muitos outros municípios brasileiros. }\end{array}$ \\
\hline $\begin{array}{l}\text { Otimização dos recursos } \\
\text { existentes e redução dos } \\
\text { desperdícios }\end{array}$ & $\begin{array}{l}\text { Políticas públicas existem, entretanto, existe a necessidade de intensificar } \\
\text { programas de sustentabilidade em todos os municípios. }\end{array}$ \\
\hline $\begin{array}{l}\text { Desenvolvimento de novas } \\
\text { tecnologias }\end{array}$ & $\begin{array}{l}\text { Modesto do desenvolvimento do setor de P\&D no país. Necessidade de incentivar } \\
\text { as indústrias de startup. }\end{array}$ \\
\hline $\begin{array}{l}\text { Políticas públicas para a } \\
\text { implementação do conceito } \\
\text { cidades inteligentes }\end{array}$ & $\begin{array}{l}\text { Programa cidade digital e Programa Cidade Inteligente, entretanto existe a } \\
\text { necessidade de ampliar os programas atuais e incentivar outras áreas de } \\
\text { desenvolvimento. }\end{array}$ \\
\hline $\begin{array}{l}\text { Informação como diferencial } \\
\text { competitivo }\end{array}$ & $\begin{array}{l}\text { Exemplo do centro de operações da cidade do rio de Janeiro. Informação em tempo } \\
\text { real garantindo ações rápidas e integradas entre polícia civil, bombeiro, engenharia } \\
\text { de tráfego e prefeitura do município. Necessidade de expandir experiência em } \\
\text { outras localidades do país. }\end{array}$ \\
\hline
\end{tabular}




\begin{tabular}{|l|l|}
\hline $\begin{array}{l}\text { Novo conceito espacial para } \\
\text { organização dos municípios }\end{array}$ & $\begin{array}{l}\text { Estatuto da cidade, trata de um grande avanço, mais ainda requer a implementação } \\
\text { de leis que regulam o espaço urbano do município. Alguns casos bem-sucedidos } \\
\text { como DF, Palmas e Salvador. }\end{array}$ \\
\hline Criativa & $\begin{array}{l}\text { Dados sendo monitorados pelo Governo Federal, entretanto ainda faltam políticas } \\
\text { voltadas ao incentivo de geração de riqueza através do crescimento intelectual dos } \\
\text { cidadãos do município. }\end{array}$ \\
\hline Colaborativa, participativa & $\begin{array}{l}\text { Pouco mencionado como praticado no contexto brasileiro. Necessidades de } \\
\text { incentivos vindo do Governo Federal para que experiências de municípios sejam } \\
\text { compartilhadas. }\end{array}$ \\
\hline Novos modelos de negócios & $\begin{array}{l}\text { Novos modelos surgindo, como por exemplo, medidores de inteligentes de smart } \\
\text { (rede inteligente) e o cartão cidadão, ambos na cidade de Barueri. }\end{array}$ \\
\hline
\end{tabular}

Fonte: Adaptado de Jordão (2016, p. 62).

A partir destes indicadores a autora analisou de forma comparativa o nível da cidade inteligente do Brasil em relação a outros países do mundo e concluiu que existe um distanciamento entre o conceito de cidade inteligente e as práticas dos países. (JORDÃO, 2016).

"A importância de buscar equiparar ao modelo global ampara-se basicamente no entendimento de que o Brasil está inserido em uma economia globalizada de mercados". (JORDÃO, 2016, p. 63). Além da identificação do distanciamento o estudo é importante para identificar os pontos que precisam ser melhorados a fim de alcançar benefícios com o desenvolvimento de práticas de sucesso conforme o modelo global de cidade inteligente.

Um modelo de cidade inteligente precisa apresentar características básicas tais como, ser sustentável, criativa e digital, pois "o desenvolvimento conjunto desses aspectos resultará no desenvolvimento socioeconômico e cultural de uma cidade" (JORDÃO, 2016 p. 82). Estes aspectos podem ser contemplados no planejamento e na gestão do espaço urbano.

Figura 1: Indicadores de sustentabilidade, criatividade e digitalização

\section{$\mathrm{ICI}$}



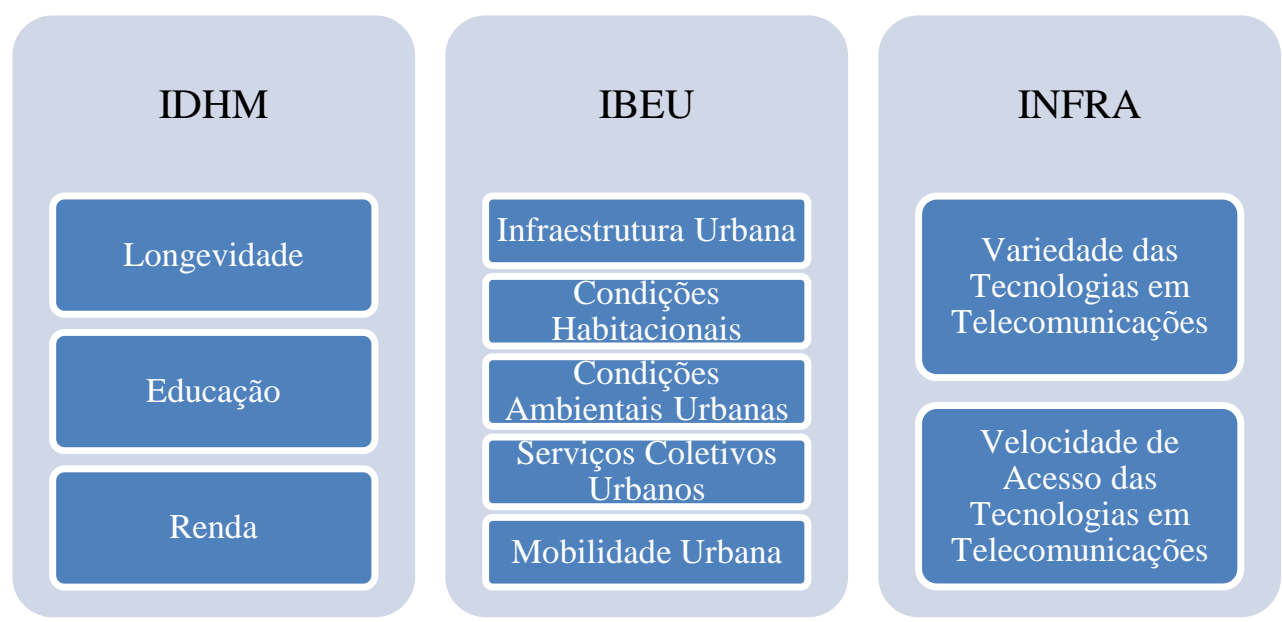

Fonte: Adaptado de Jordão (2016, p. 62).

Segundo a autora, três indicadores (sustentabilidade, criatividade e digitalização), podem ser utilizados para mensurar o nível de inteligência das cidades brasileiras. Para mensurar a criatividade, desenvolvimento econômico da população e capacidade produtiva usa-se o IDHM - Índice de Desenvolvimento Humano do Município. O nível de sustentabilidade pode ser mensurado pelo IBEU - Índice de Bem-estar Urbano. Este é composto por cinco serviços básicos (fornecimento de água, tratamento de esgoto sanitário e coleta de lixo), condições habitacionais e mobilidade urbana. E, por fim, para mensurar o nível de digitalização pode ser utilizado o IINFRA - Índice de Infraestrutura por Município. (JORDÃO, 2016).

Conforme Kon e Santana (2016, p. 127) "a necessidade de tornar as cidades mais inteligentes justifica-se pelos benefícios gerados, e destaca os principais benefícios: otimização da infraestrutura e serviços da cidade; uso mais sustentável dos recursos e melhoria da qualidade de vida da população". De acordo com os conceitos estudados verifica-se que há uma reconfiguração no modo de fazer o planejamento urbano, que se tornou quase que diário com ações complexas e multifacetadas que variam de acordo com as necessidades da cidade.

\section{MATERIAIS E MÉTODOS}

Este estudo, de natureza qualitativa, exploratória e descritiva, teve como principal método a pesquisa de campo para apresentaras transformações em inovações na gestão do território urbano em Capão da Canoa na região do litoral norte do Rio Grande do Sul.

$\mathrm{O}$ estudo utilizou pesquisa bibliográfica para compreender os conceitos e indicadores de modelos de cidades inteligentes, destacando seus princípios fundamentais. 
Para a pesquisa de campo utilizou-se como objeto de estudo o GGI - Gabinete de Gestão Integrada, instituído pela Lei Municipal 2707/2011 cuja implementação constituise em uma parceria entre Prefeitura Municipal de Capão da Canoa/RS e Brigada Militar (BM), envolvendo as esferas do Governo Estadual e órgãos representativos. Aporte financeiro para aquisição de equipamentos, espaço físico para o gabinete, aporte técnico e responsabilidade pela gestão do gabinete (monitoramento) foram necessários para implementação e funcionalidade do gabinete. Além disso, foram definidos alguns pontos estratégicos da cidade para a instalação do sistema de cercamento eletrônico e reconhecimento facial, como por exemplo os principais pontos de acesso à cidade, Avenida Beira-mar e algumas praças do município. Atualmente o GGI conta com 180 câmeras espalhadas pelo município que possibilitam o acompanhamento das imagens em tempo real contribuindo com a polícia em investigações.

Para a análise dos dados os autores buscaram destacar, de maneira descritiva e qualitativa, os conceitos estudados e os principais e mais relevantes aspectos do processo de implementação da tecnologia de monitoramento por câmeras como instrumento de gestão da segurança urbana e demais serviços ao cidadão no município de Capão da Canoa/RS.

\section{RESULTADOS E DISCUSSÃO}

Com base neste breve estudo cujo objetivo foi o de investigar como a tecnologia da informação pode contribuir para a gestão da segurança urbana, identificando a eficiência do seu uso e apresentando algumas de suas contribuições, apresenta-se o sistema de monitoramento por vídeo como instrumento de gestão territorial, que contribui de maneira relevante para a segurança urbana, visto que pode beneficiar os moradores e visitantes em vários serviços.

O GGI, lançado oficialmente em junho de 2018, tratou inicialmente de tornar a cidade mais digital em termos de segurança, com pontos de Wi-Fi, o Digibus e o Fala Cidadão. Pode-se considerar um avanço em relação aos diversos modelos de cidades inteligentes conhecidos no Brasil e no mundo, apresentados neste estudo.

$\mathrm{Na}$ busca por tentar transformar a gestão da cidade mais digital a prefeitura municipal implementou além do GGI o aplicativo "Capão + Segura” no qual, moradores e comerciantes, puderam integrar suas câmeras de videomonitoramento com o sistema já 
existente. Além disso, pontos de Wi-fi foram instalados e liberados nas praças e áreas públicas. Também foi implementado o sistema de acompanhamento de localização em tempo real do ônibus, o "Digibus". Por fim, outro aplicativo importante em funcionamento é o "Fala, Cidadão", uma ferramenta onde a comunidade pode informar ao executivo local os problemas em ruas, na iluminação, na saúde e demais situações.

Sabe-se que as cidades desafiam a gestão municipal, pois apresentam uma diversidade de necessidades e possibilidades. Nery, em seus estudos sobre urbanidade, especificamente na cidade de São Paulo, corrobora nossa visão:

Para lidar com os desafios impostos pela heterogeneidade urbana uma possibilidade promissora é selecionar as variáveis de interesse, compatibilizar as informações em termos espaciais e temporais e estratificar o território municipal em diferentes padrões urbanos e demográficos, com a subsequente delimitação de subáreas. Isso asseguraria a análise da heterogeneidade e hierarquização espaciais que caracterizam a metrópole paulistana. Assim desenvolvendo políticas, planejamento e gestão adequados a lugares e momentos específicos. (NERY, 2019, p. 01).

Com base nas análises bibliográficas e do estudo de campo, este estudo recomenda uma proposta de criação de indicadores que poderão contribuir para a gestão pública municipal e órgãos envolvidos, possibilitando avaliar melhor os resultados do GGI, ampliando os indicadores apresentados que utilizam dados qualitativos e quantitativos. As informações divulgadas até o momento, trazem aspectos positivos da implementação do GGI como ferramenta que auxilia diariamente a Brigada Militar e a Polícia Civil em investigações.

A seguir apresenta-se os primeiros dados divulgados pela Prefeitura Municipal de Capão da Canoa, referentes ao trimestre - junho a agosto - dos anos de 2017e 2018 em que se observa uma redução nos índices de criminalidade no município.

Tabela 1: Índices de criminalidade - Capão da Canoa/RS - trimestre jun-ago (2017-2018)

\begin{tabular}{|c|c|c|c|c|c|c|c|c|c|}
\hline \multirow[b]{2}{*}{ INDICADORES } & \multicolumn{4}{|c|}{2017} & \multicolumn{4}{|c|}{2018} & \multirow[b]{2}{*}{ Variação \% } \\
\hline & Junho & Julho & Agosto & $\begin{array}{l}\text { Total } \\
\text { Trim. }\end{array}$ & Junho & Julho & Agosto & $\begin{array}{l}\text { Total } \\
\text { Trim. }\end{array}$ & \\
\hline Homicídio Doloso & 1 & 3 & 1 & 5 & 2 & 1 & 1 & 4 & $-20,00 \%$ \\
\hline Furtos & 81 & 100 & 87 & 268 & 66 & 91 & 92 & 249 & $-7,09 \%$ \\
\hline Furto de Veículo & 7 & 6 & 3 & 16 & 14 & 6 & 6 & 26 & $62,50 \%$ \\
\hline Roubos & 43 & 28 & 28 & 99 & 27 & 17 & 23 & 67 & $-32,32 \%$ \\
\hline Roubo de Veículo & 5 & 1 & 2 & 8 & 4 & 2 & 2 & 8 & $0,00 \%$ \\
\hline
\end{tabular}


Revista Tecnologia e Ambiente, v. 27, 2021, Criciúma, Santa Catarina/SC - ISSN Eletrônico 2358-9426 e ISSN Impresso 1413-8131

\begin{tabular}{lccccccccc}
\hline Latrocínio & 0 & 0 & 0 & $\mathbf{0}$ & 0 & 0 & 0 & $\mathbf{0}$ & - \\
\hline Estelionato & 11 & 11 & 11 & $\mathbf{3 3}$ & 15 & 13 & 20 & $\mathbf{4 8}$ & $45,45 \%$ \\
\hline $\begin{array}{l}\text { Delitos } \\
\begin{array}{l}\text { Relacionados à } \\
\text { Armas e Munições }\end{array}\end{array}$ & 4 & 1 & 1 & $\mathbf{6}$ & 2 & 0 & 4 & $\mathbf{6}$ & $0,00 \%$ \\
\hline $\begin{array}{l}\text { Delitos } \\
\begin{array}{l}\text { Relacionados à } \\
\text { Corrupção }\end{array}\end{array}$ & 0 & 0 & 0 & $\mathbf{0}$ & 0 & 0 & 0 & $\mathbf{0}$ & - \\
\hline $\begin{array}{l}\text { Entorpecentes - } \\
\text { Posse }\end{array}$ & 5 & 8 & 6 & $\mathbf{1 9}$ & 3 & 3 & 2 & $\mathbf{8}$ & $-57,89 \%$ \\
\hline $\begin{array}{l}\text { Entorpecentes - } \\
\text { Tráfico }\end{array}$ & 10 & 7 & 13 & $\mathbf{3 0}$ & 5 & 3 & 6 & $\mathbf{1 4}$ & $-53,33 \%$ \\
\hline $\begin{array}{l}\text { Sequestro e Cárcere } \\
\text { Privado }\end{array}$ & 0 & 0 & 0 & $\mathbf{0}$ & 0 & 0 & 0 & $\mathbf{0}$ & - \\
\hline $\begin{array}{l}\text { Sequestro } \\
\text { Relâmpago }\end{array}$ & 0 & 0 & 0 & $\mathbf{0}$ & 0 & 0 & 0 & $\mathbf{0}$ & - \\
\hline Total & $\mathbf{1 6 7}$ & $\mathbf{1 6 5}$ & $\mathbf{1 5 2}$ & $\mathbf{4 8 4}$ & $\mathbf{1 3 8}$ & $\mathbf{1 3 6}$ & $\mathbf{1 5 6}$ & $\mathbf{4 3 0}$ & $-11,16 \%$ \\
\hline
\end{tabular}

Fonte: PMCC (2018)

Ampliando os controles de resultados, a gestão pública poderá comprovar os benefícios e justificar aos demais órgãos envolvidos a importância de manter e realizar novos investimentos em inovação tecnológica no processo de gestão da segurança urbana.

É fundamental que seja feito uma análise dos elementos que compõem a estrutura urbana e dos processos de crescimento da cidade. Portanto, é importante destacar que a elaboração de indicadores deve ser feita de maneira multifacetada com participação de vários agentes do planejamento urbano e segurança pública. A busca por soluções aos problemas urbanos precisa ser analisada com uma "visão integrada e interdisciplinar do funcionamento das cidades, atuando de forma cada vez mais transversal'. (CHIQUETTO, 2019, p. 01) É preciso ampliar o debate sobre a gestão do espaço urbano articulando diversos setores tais como: as instituições de ensino, as diferentes esferas de governo, o setor privado, a população, as ONGs, entre outros, na busca por respostas eficientes aos problemas atuais, pois o crescimento do crime urbano e o temor gerado por ele estimulam a produção e publicação de registros criminais, "o que aumenta a demanda da sociedade civil, da política, de parte da mídia e das próprias corporações policiais por serviços que minimizem a criminalidade”. (NERY, 2019, p. 01).

A seguir elenca-se a sugestão de indicadores que, somados aos já existentes, alinhados aos objetivos do município e adequados a sua realidade, poderão servir como fonte de informação para tomada de decisão e avaliação da eficiência dos fins para os 
quais foi concebido o GGI. Tais medidas contribuirão para uma Capão da Canoa mais digital aproximando-a do conceito de cidade inteligente que contemple, além da segurança pública, outras áreas, tais como: mobilidade urbana, gerenciamento de tráfego, transporte público, transporte comercial, serviços de emergência, serviços públicos, inclusão digital e demais aspectos relacionados a qualidade de vida urbana.

Quadro 3 - Indicadores propostos ao GGI

\begin{tabular}{|l|l|}
\hline INDICADORES & AÇÕES DE CONTROLE \\
\hline Infraestrutura em Telecomunicações & $\begin{array}{l}\text { Qualidade do Wi-fi free para acesso à internet em praças e demais espaços } \\
\text { públicos. }\end{array}$ \\
\hline $\begin{array}{l}\text { Serviços voltados para melhorar a } \\
\text { qualidade de vida do cidadão }\end{array}$ & $\begin{array}{l}\text { Quais e quantos serviços são oferecidos ao cidadão por meio eletrônico? } \\
\text { (Educação - acompanhamento escolar e Saúde - marcação de consultas) }\end{array}$ \\
\hline $\begin{array}{l}\text { Otimização dos recursos existentes e } \\
\text { redução dos desperdícios }\end{array}$ & Identificar a redução de custos como uso de TIC's. \\
\hline Desenvolvimento de novas tecnologias & Incentivar o uso de novas tecnologias. \\
\hline $\begin{array}{l}\text { Políticas públicas para a implementação } \\
\text { do conceito cidades inteligentes }\end{array}$ & $\begin{array}{l}\text { Identificar quais programas que incentivam o conceito de cidade } \\
\text { inteligente e cidade digital para então enquadrar-se. }\end{array}$ \\
\hline Sustentabilidade & $\begin{array}{l}\text { Identificar aspectos de melhoria quanto à mobilidade urbana, poluição } \\
\text { sonora e controle do descarte irregular de resíduos sólidos; como pode ser } \\
\text { gerado informações sobre clima e tempo prevendo possíveis desastres } \\
\text { naturais. }\end{array}$ \\
\hline $\begin{array}{l}\text { Informação como diferencial } \\
\text { competitivo }\end{array}$ & $\begin{array}{l}\text { Determinar os canais de informações ao cidadão promovendo a } \\
\text { universalização e transparência dessas informações. }\end{array}$ \\
\hline $\begin{array}{l}\text { Novo conceito espacial para organização } \\
\text { dos municípios }\end{array}$ & $\begin{array}{l}\text { Identificar as contribuições para a organização espacial da cidade; } \\
\text { capacitar os colaboradores envolvidos (gestores) para o uso de TIC's na } \\
\text { gestão pública. }\end{array}$ \\
\hline Criativa & $\begin{array}{l}\text { Identificar áreas em que demais organizações e entidades possam } \\
\text { contribuir com o processo de inovação. }\end{array}$ \\
\hline Colaborativa, participativa & $\begin{array}{l}\text { Estabelecer novas parcerias e integração com outras redes de } \\
\text { monitoramento do litoral norte do Rio Grande do Sul. } \\
\text { Avaliar a integração do sistema de monitoramento com os demais } \\
\text { departamentos. Ex: Bombeiros, defesa civil, abastecimento de água e } \\
\text { energia elétrica. }\end{array}$ \\
\hline Novos modelos de negócios & $\begin{array}{l}\text { Estabelecer uma interconexão com as empresas locais envolvendo os } \\
\text { aspectos econômicos, sociais da gestão pública municipal. }\end{array}$ \\
\hline
\end{tabular}

Fonte: Adaptado de Jordão (2016)

Acredita-se que, no âmbito do planejamento, execução e controle, o GGI apresenta-se carente de instrumentos de controles mais abrangentes, que demonstrem transparência nos resultados, visto que não foram disponibilizados dados concretos com relação a números que apontem o grau de eficiência amplo. 
De acordo com os estudos apresentados por Cunha et al (2016) a integração dos sistemas de segurança urbana permite compartilhar informações entre outros âmbitos da cidade e cita como exemplo, polícia, guarda municipal, bombeiros e serviços de saúde.

Essa abrangência é possível, tendo em vista a potencialidade das ferramentas tecnológicas já implementadas. Como exemplo, podemos citar a capacidade de processamento e análise de um grande volume de dados relacionados ao controle e gestão de tráfego, determinando bloqueio de vias de acesso ou de avenidas, evitando grandes congestionamentos em períodos de temporada de verão, informando o visitante sobre os possíveis desvios ou rotas alternativas.

Salienta-se que durante a realização deste estudo, na tentativa de identificar alguns dados, os autores encaminharam, por e-mail, aos responsáveis pelo GGI da prefeitura municipal, alguns questionamentos, seguidos de inúmeras visitas pessoais ao departamento, mas até o momento e prazo para submissão deste artigo não obtiveram resposta. Da mesma forma não foram disponibilizados relatórios para compor esta pesquisa. Espera-se que este estudo chame a atenção dos responsáveis para tal demanda e que, em um futuro breve, se consiga esclarecer, de forma mais profunda, alguns questionamentos.

\section{CONSIDERAÇÕES FINAIS}

Com este estudo, foi possível compreender e analisar pontos fortes e fracos do GGI - Gabinete de Gestão Integrada que se constitui em uma estrutura de monitoramento por câmeras com recursos de reconhecimento facial e leitura de placas de veículos, sendo possível identificar fugitivos do sistema prisional, bem como carros roubados. Sua gestão é realizada por servidores da reserva da Brigada Militar em parceria com a Prefeitura Municipal, articulados com a Polícia Civil em combate e prevenção da violência.

Existem aspectos positivos com a implementação da tecnologia, pois a gestão municipal pode se beneficiar melhorando sua capacidade de gestão patrimonial, visto que alguns casos de vandalismos contra o patrimônio público, furtos e outros crimes puderam ser facilmente resolvidos com o uso das câmeras de monitoramento. Além de requalificar a segurança urbana no município de Capão da Canoa com reflexos em todo o litoral norte do Rio Grande do Sul. 
Contudo, este estudo aponta a necessidade de indicadores de controle, que sirvam de parâmetro para avaliar o progresso na busca de soluções de problemas urbanos. Para tanto sugerem-se os seguintes: Infraestrutura em Telecomunicações; Serviços voltados para melhorar a qualidade de vida do cidadão; Otimização dos recursos existentes e redução dos desperdícios; Desenvolvimento de novas tecnologias; Políticas públicas para o avanço na implementação do conceito de cidade inteligente; Sustentabilidade; Informação como diferencial competitivo; Novo conceito espacial para organização dos municípios; Criativa; Colaborativa, participativa e possibilitar novos modelos de negócios.

Os autores entendem que, passados pouco mais de um ano da implementação do sistema, são poucos os dados prontos a serem divulgados de maneira transparente à comunidade em geral. Além disso, acredita-se que para o avanço no conceito de cidade inteligente, o município de Capão da Canoa precisa ampliar seus controles, de forma a ter um maior aproveitamento do investimento realizado. Isso é possível, visto que os primeiros passos já foram dados.

Acredita-se que, para um planejamento e gestão do território urbano com qualidade, é necessário que a gestão municipal se preocupe com o presente e o futuro, aliando-se aos avanços tecnológicos para proporcionar qualidade de vida, qualificando os serviços públicos de acordo com as exigências para o bem-estar humano no território.

\section{REFERÊNCIAS}

BARBOSA, Simone D. J.; Silva, Bruno Santana da S. Interação humano computador. Rio de Janeiro: Elsevier, 2010.

BARROSO, Elvira Maria Fernandes. A responsabilidade do Poder Público no planejamento e gestão da cidade. 2012. Disponível em: https://jus.com.br/artigos/21915/a-responsabilidade-do-poder-publico-no-planejamentoe-gestao-da-cidade Acesso em: 25 mar 2019.

BRASIL. Constituição (1988). Constituição da República Federativa do Brasil. Brasília, DF: Senado Federal, 1988.Disponível em: https://www.senado.leg.br/atividade/const/con1988/con1988_14.12.2017/art_182_.asp. Acesso em: 24 jun 2019.

CAPÃO DA CANOA. Após criação do GGI, Capão da Canoa reduz índices de criminalidade. Disponível em: $<$ http://www.capaodacanoa.rs.gov.br/site/noticia/visualizar/id/4459/?Apos-criacao-doGGI-Capao-da-Canoa-reduz-indices-de-criminalidade.html>. Acesso em 20 ago 2019

CANOAS. Observatório de Segurança Pública de Canoas. Disponível em: https://www.canoas.rs.gov.br/servicos/observatorio-de-seguranca/. Acesso em: 24 jun 2019. 
COREDE LITORAL (Osório). Planejamento Estratégico COREDE Litoral. Osório:

2017.

Disponível

em:

<http://planejamento.rs.gov.br/upload/arquivos/201710/09144219-plano-litoral.pdf>.

Acesso em: 25 maio 2019.

COREDE. Planejamento Estratégico Corede Litoral Norte. 2010/2011. Disponível em:<https://www.google.com.br/search?q=PLANEJAMENTO+ESTRAT\%C3\%89GIC O+COREDE+LITORAL+NORTE\&aqs=chrome..69i57.653j0j8\&sourceid=chrome\&ie $=\mathrm{UTF}-8>$. Acesso em: 20 ago 2019.

CHIQUETTO, Julio B. Mobilidade Urbana e Poluição do Ar - Sinergias e Cobenefícios.

2019. Disponível em: <http://www.iea.usp.br/pesquisa/projetos-institucionais/uspcidades-globais/artigos-digitais/mobilidade-urbana-e-poluicao-do-ar-sinergias-ecobeneficios>. Acesso em 20 out 2019.

CUNHA, Maria Alexandra. Et at. Smartcitties: Transformação digital de cidades. São Paulo: PGPC - Programa Gestão Pública e Cidadania. 2016.

DASSEN, Ton. Cidades Inteligentes - novos agentes de mudança. 2014. Disponível em: <https://www.kas.de/c/document_library/get_file?uuid=48501de1-9b11-27a5-9697-

d7fbcacf04fe\&groupId=265553> . Acesso em 20 out 2019.

GOMES, Paulo Cesar da Costa. A condição urbana: ensaios de geopolítica da cidade. Rio de Janeiro: Bertrand Brasil, 2010.

GONÇALVES, Teresinha Maria. A contribuição do pensamento dialético de Henri Lefebvre para a pesquisa interdisciplinar sobre a questão urbana. 2016. Disponível em: <http://periodicos.unesc.net/tecnoambiente/article/view/2793>. Acesso em 20 out 2019.

JORDÃO, Kelem Christine Pereira. Cidades Inteligentes: uma proposta viabilizadora para a transformação das cidades brasileiras. Campinas: PUC. 2016.

KON, Fabio; SANTANA, Eduardo Felipe Zambom. Cidades Inteligentes: Conceitos, plataformas e desafios. São Paulo: IME-USP, 2016.

MINUSCOLI, Alcenir Luis; ALMEIDA, Luis Henrique Fogaça de. Afinal o que é segurança pública. Disponível em:<https://jus.com.br/artigos/51752/afinal-o-que-eseguranca-publica> Acesso em 17 out 2019.

NERY, Marcelo Batista. Crime e Violências. 2019. Disponível em: $<$ http://www.iea.usp.br/pesquisa/projetos-institucionais/usp-cidades-globais/artigosdigitais/crime-e-violencias>. Acesso em 20 Out de 2019.

VASCONCELOS, H.; MENDES, L. Tecnologia Contra a Violência. Gaúcha/ZH. 2018. Porto Alegre. 08 de junho de 2018.Seção Gaúcha ZH Segurança, p.01

Disponível em: https://gauchazh.clicrbs.com.br/seguranca/noticia/2018/06/um-em-cadaquatro-municipios-do-rs-tem-cameras-para-combater-a-criminalidade-

cji6bclqa0bp601 panx 7ube64.htmlAcesso em: 22 maio 2019. 